\title{
CHANGES IN ANTIOXIDANT ENZYMES ACTIVITIES AND PROLINE, TOTAL PHENOL AND ANTHOCYANINE CONTENTS IN HYSSOPUS OFFICINALIS L. PLANTS UNDER SALT STRESS
}

\author{
Omolbanin Jahantigh, ${ }^{1}{ }^{*}$ Farzaneh Najafi, ${ }^{1}$ Hassanali Naghdi Badi, ${ }^{2}$ \\ RamaZan Ali Khavari-NeJad ${ }^{1,3}$ and Forough Sanjarian ${ }^{4}$ \\ ${ }^{1}$ Department of Plant Sciences, Faculty of Biological Sciences, Kharazmi University, \\ Postal Code 15719-14911, Tehran, Iran \\ 2Institute of Medicinal Plants, Medicinal Plants Research Center, ACECR, Karaj, Iran \\ ${ }^{3}$ Department of Biology, Faculty of Sciences, Islamic Azad University, \\ Science and Research Branch, Tehran, Iran \\ ${ }^{4}$ National Institute of Genetic Engineering and Biotechnology (NIGEB), Tehran, Iran
}

(Received: September 10, 2015; accepted: October 19, 2015)

\begin{abstract}
The relationships between salt stress and antioxidant enzymes activities, proline, phenol and anthocyanine contents in Hyssopus officinalis L. plants in growth stage were investigated. The plants were subjected to five levels of saline irrigation water, 0.37 (tap water as control) with 2, 4, 6, 8 and $10 \mathrm{dSm}^{-1}$ of saline water. After two months the uniform plants were harvested for experimental analysis. Antioxidant enzymes activities and proline, phenol and anthocyanine contents of the plants were examinated. Enhanced activities of peroxidase, catalase and superoxide dismutase were determined by increasing salinity that plays an important protective role in the ROS-scavenging process. Proline, phenol and anthocyanine contents increased significantly with increasing salinity. These results suggest that salinity tolerance of Hyssopus officinalis plants might be closely related with the increased capacity of antioxidative system to scavenge reactive oxygen species and with the accumulation of osmoprotectant proline, phenol and anthocyanine contents under salinity conditions.
\end{abstract}

Keywords: Abiotic stress - antioxidant enzymes - proline - salinity - Hyssopus officinalis

\section{INTRODUCTION}

Soil salinity is one of the most dangerous environmental stresses that can induce oxidative stress in plants. Biochemical and physiological responses to salt stress in plants alters and almost all plant processes are affected $[12,20]$. The major effect of salinity is the inhibition of plant growth possibly by reducing enzymatic activities and biochemical constituents [21]. One of the biochemical responses of plants to salt stress is the production of reactive oxygen forms (ROS) which disturb in turn the balance between ROS production and disappearance of their effects by antioxidant enzymes thus, causes oxidative damage to lipids, proteins, and nucleic acids [27, 28]. To overcome the negative consequences of salt stress, plants have evolved various protective mechanisms either to reduce or to completely remove ROS. One of the

*Corresponding author; e-mail address: omolbaninjahantigh@yahoo.com 
protective mechanisms is the change in enzymatic antioxidant activity, which operates with a sequential and simultaneous action of many enzymes such as superoxide dismutase, peroxidase, and catalase, which react with ROS to keep it at low level. The salt tolerant plants for effective removal of ROS are an efficient antioxidant system [27]. The relationship between salinity or drought diverse environment and the inner surface of the water-soluble antioxidants (anthocyanins) or antioxidant enzymes have been reported [40]. Phenolics represent a chemically diverse group of compounds produced by a large number of metabolic pathways. A phenolic is characterised by the presence of an aromatic ring bearing one or more hydroxyls, and these compounds occur in both monomeric and polymeric forms, e.g. condensed tannins. The ecological and physiological activities of phenolic compounds in the plants are diverse and highly variable [32]. Phenols and polyphenolic compounds such as flavonoids, act as antioxidants and cytotoxic effects of oxygen radicals in plant cells are removed [25]. The high amount of phenols and flavonoids in extracts may explain their high antioxidative activities [32]. Anthocyanins are a large group of water-soluble pigments of the family of flavonoids which are found in all plant tissues and are mainly responsible for the colour of plants and fruits organic herbs [19]. These substances are accumulated in various tissues and are influenced by various environmental stimuli [10]. Proline accumulation is a common metabolic response when higher plants are exposed to water deficits and high salinity. Proline acts as an osmolyte that not only stabilizes protein structures, but also acts as the regulator of cellular redox potential [37]. Medicinal plants have long been paid attention and in traditional medicine they have been used when treating many diseases. It has been recognized that the direct and indirect effects of industrialization on human societies cause diseases, such as heart disease, diabetes, cancer, in most urban communities. Therefore, identification and cultivation of plants in large human communities can help to cure the disease. Although, much progress has been made in synthetic organic chemistry, medicinal plants still make up about $25 \%$ of prescription drugs [22]. Hyssop (Hyssopus officinalis L.) from the family of Lamiaceae has been used for hundreds of years as an important culinary and medicinal plant. It is native to the Caucasus, North-Western Iran, the Turkish North Eastern Black Sea region, and Southern Anatolia [23]. It has a very strong spicy taste and pungent flavour. It is commonly used in traditional medicine. Hyssop extracts and oil may be found as flavour ingredient in many food products, mainly sauces and seasonings, also in bitters and liqueurs. The oil is a fragrance component in soaps, cosmetics and perfumes, especially in eau de cologne and oriental bases [39]. Extracts from the leaves are antimicrobial, mildly spasmolytic [41] and exhibit strong antiviral activity against HIV [16]. Although, hyssop herb is valued and widely cultivated in the world, no information is available on the response of the plant to salinity. Hence, the effect of salinity on the activity of antioxidant enzymes and levels of phenolic compounds and anthocyanin defense mechanism to better understand hyssop under salt stress were studied. 


\section{MATERIALS AND METHODS}

Hyssop seeds (Hyssopus officinalis L.) were obtained from the Institute of Medicinal Plants Research of Iranian Academic Center for Education, Culture and Research (ACECR), Tehran, Iran. Ten seeds per plastic pot $(30 \mathrm{~cm}$ diameter and $50 \mathrm{~cm}$ height) were sown. The pots were transferred to the greenhouse of the ACECR in a controlled environment of $25 / 15{ }^{\circ} \mathrm{C}$ day/night temperatures, $16 \mathrm{~h}$ photoperiod, $70 \%$ relative humidity and $400 \mu \mathrm{mol} \mathrm{m}^{-2} \mathrm{~s}^{-1}$ photon flux density. The four-month-old plants were then transferred to 5-liter containers filled with air-dried clay loam soil. After two weeks from the planting date, the plants were subjected to five levels of saline irrigation water, 0.37 (tap water as control) with $2,4,6,8$ and $10 \mathrm{dSm}^{-1}$ of saline water. The plants were placed in a greenhouse under controlled conditions above. Natural saline water was obtained from Hoz-e-Soltan Lake in Qom, Iran. Upon examination of the saline water sampled from Hose-e-sultan Lake the major ions were found in it: $\mathrm{Na}^{+} 112 \mathrm{~g} \mathrm{l}^{-1}, \mathrm{~K}^{+} 1.17 \mathrm{~g} \mathrm{l}^{-1}, \mathrm{Cl}^{-} 191 \mathrm{~g} \mathrm{l}^{-1}, \mathrm{Mg}^{2+} 6.26 \mathrm{~g} \mathrm{l}^{-1}, \mathrm{Ca}^{2+} 0.2 \mathrm{~g} \mathrm{l}^{-1}, \mathrm{SO}_{4}{ }^{2-} 26.9$ $\mathrm{g} \mathrm{l}^{-1}, \mathrm{CO}_{3}^{2-} 0.069 \mathrm{~g} \mathrm{l}^{-1}$ and $\mathrm{HCO}_{3}^{-} 0.073 \mathrm{~g} \mathrm{l}^{-1}$. Saline treatments were applied for two months and at the completion of this period, plants were harvested. The roots and aerial parts were subjected to assay some physiological parameters. Measurement of physiological parameters was carried out at the Plant Physiology Lab, Faculty of Biological Sciences, Kharazmi University, Tehran, Iran. Phosphate buffer $\left(0.1 \mathrm{M} \mathrm{L}^{-1}\right.$; pH 6.8) was used to extract the enzyme. In order to calculate enzyme activities, protein contents were determined according to Bradford [8]. Superoxide dismutase (SOD) activity was assayed by monitoring its inhibition of the photochemical reduction of metyltiazol tetrazolium (MTT). One unit of enzyme activity was defined as the quantity of enzyme that reduced the A560 of control by $50 \%$ [18]. Guayacol proxidase (GPX) activity was assayed according to Dazy et al. [15] and enzyme activity was calculated based on the changes in absorbance at $470 \mathrm{~nm}$ per min per $\mu \mathrm{g}$ protein. Catalase (CAT) activity was assayed by [11] and enzyme activity was calculated based on the changes in absorbance at $240 \mathrm{~nm}$ per min per $\mu$ g protein. To measure proline contents, fresh parts were homogenized in 3\% sulfosalicylic acid. Proline contents of the samples were determined according to Bates et al. [5]. Total phenolic contents of the samples were determined using the Folin-Ciocalteu reagent assay [34], with gallic acid as standard. Acidic methanol (methanol $99.5 \%$ and $\mathrm{HCl} 1 \%$, ratio 99 at 1) was used to extract the anthocyanin. Fresh leaves were homogenized in $5 \mathrm{ml}$ acidic methanol and then were set aside for 24 hours at $4{ }^{\circ} \mathrm{C}$ in dark to allow anthocyanins to extract. The solution was then centrifuged at $4000 \mathrm{~g}$ for $10 \mathrm{~min}$, and the supernatant was increased by $2 \mathrm{ml}$. Finally, the absorbance of the supernatant was measured at $530 \mathrm{~nm}$ [13]. To determine the concentration of anthocyanin samples from the standard curve anthocyanin (cyanidin 3-glucoside brand Kuromanin Chloride) was used. The experiments were carried out in randomized complete block design. The data were analyzed by using one-way analysis of variance using SPSS. Each data was the mean of four replicates in each group. 


\section{RESULTS}

Responses of antioxidant enzyme activities in plants of Hyssopus officinalis to salt stress are shown in Figures 1-3. Fig. 1 shows the effects of increasing concentrations of salt stress on SOD activity. SOD activity under salinity was higher than that of

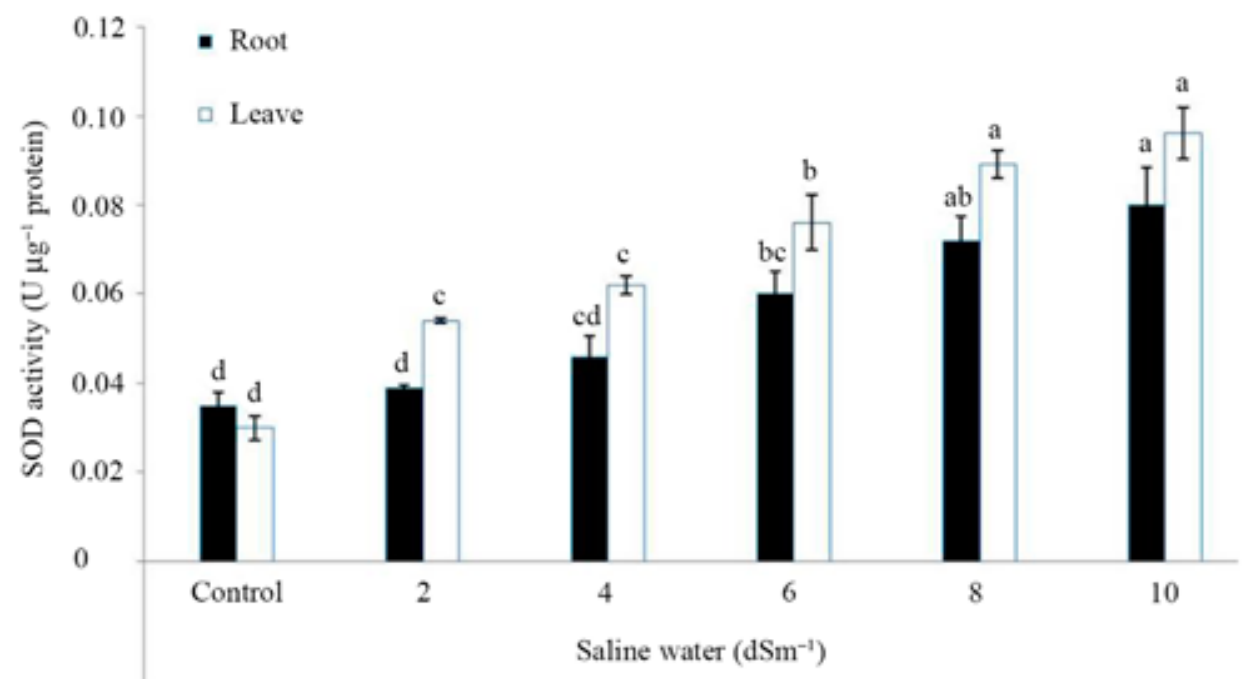

Fig. 1. Effect of salinity treatment on the activity of SOD in the roots and leaves of Hyssopus officinalis L. plants. Values are the means \pm SE from four replicates. Different letters above columns indicated significant $(\mathrm{P}<0.05)$ differences

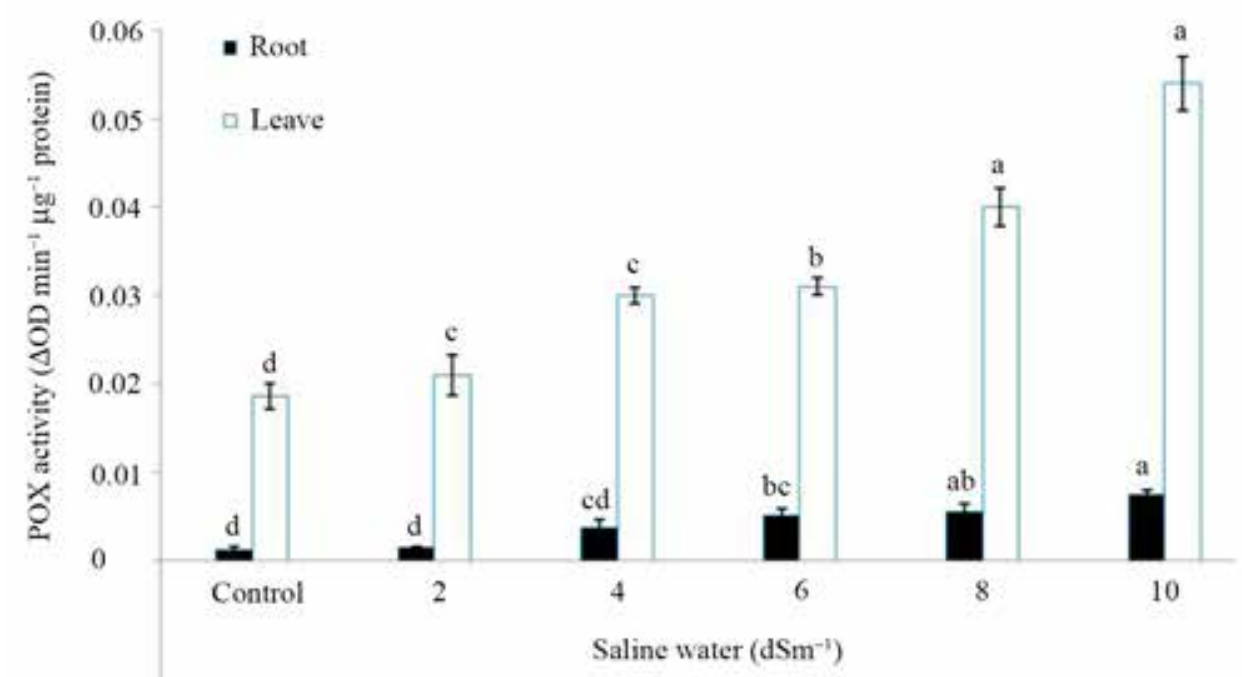

Fig. 2. Effect of salinity treatment on the activity of GPX in the roots and leaves of Hyssopus officinalis L. plants. Values are the means \pm SE from four replicates. Different letters above columns indicated significant $(\mathrm{P}<0.05)$ differences 


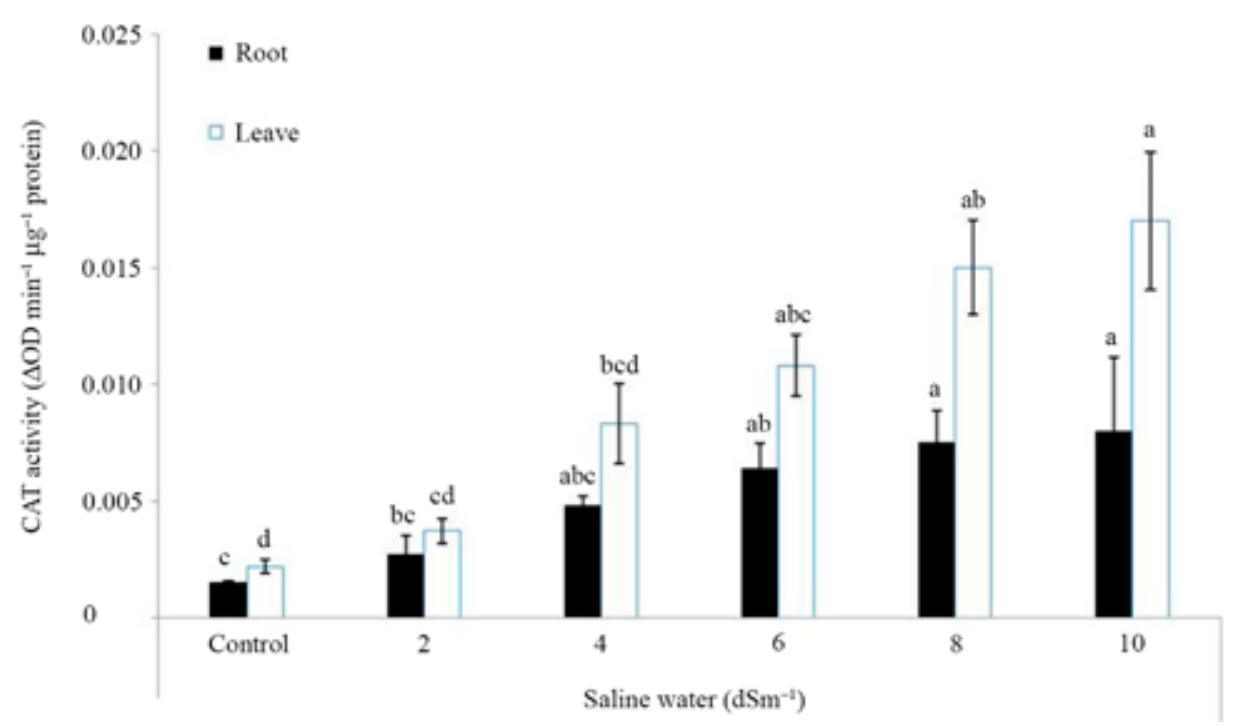

Fig. 3. Effect of salinity treatment on the activity of CAT in the roots and leaves of Hyssopus officinalis L. plants. Values are the means \pm SE from four replicates. Different letters above columns indicated significant $(\mathrm{P}<0.05)$ differences

control. SOD activity in the roots and leaves of the hyssop plants increased by increasing salinity concentration. Activity of SOD in both of roots and leaves of hyssop plants increased significantly compared with control plants (Fig. 1). The effect of increasing concentrations of salinity on peroxidase enzyme activity is shown in Figure 2. GPX activity in the leaves and roots significantly increased and in the leaves of hyssop plants more than roots (Fig. 2). In treated plants with saline water, CAT activity in the leaves and roots significantly increased and in the leaves of plants more than roots (Fig. 3). Table 1 contains the effects of increasing concentrations of salt stress on proline content. By increasing the salt concentration proline content in roots and leaves of hyssop plants increased significantly. Increased proline content in leaves was higher than in the root (Table 1). In the present study, total phenolic content in each extract was determined spectrometrically according to the FolinCiocalteu method and calculated as gallic acid equivalent (GAE). A significant differ-

Table 1

Effect of salinity treatment on the proline content $\left(\mu \mathrm{g} \mathrm{g}^{-1} \mathrm{FW}\right)$ in the roots and leaves of Hyssopus officinalis L. plants

\begin{tabular}{|l|c|c|c|c|c|c|}
\hline \multicolumn{7}{|c|}{ Saliniy treatment $\left(\mathrm{dSm}^{-1}\right)$} \\
\hline & control & 2 & 4 & 6 & 8 & 10 \\
\hline Root & $5 \pm 0.41^{\mathrm{d}}$ & $7.07 \pm 0.35^{\mathrm{c}}$ & $9.8 \pm 1.06^{\mathrm{b}}$ & $10.93 \pm 0.66^{\mathrm{ab}}$ & $11.69 \pm 0.41^{\mathrm{ab}}$ & $12.4 \pm 0.66^{\mathrm{a}}$ \\
\hline Leaf & $11.1 \pm 0.57^{\mathrm{d}}$ & $16.1 \pm 0.13^{\mathrm{c}}$ & $17.4 \pm 0.20^{\mathrm{c}}$ & $18.3 \pm 0.51^{\mathrm{bc}}$ & $20.34 \pm 1.39^{\mathrm{ab}}$ & $21.15 \pm 1.03^{\mathrm{a}}$ \\
\hline
\end{tabular}

Values are means $\pm \mathrm{SE}$. Values with similar letters are not significantly different. 
Table 2

Effect of salinity treatment on the phenol content $\left(\mathrm{mg} \mathrm{g}^{-1} \mathrm{DW}\right)$ in the roots and leaves of Hyssopus officinalis L. plants

\begin{tabular}{|l|c|c|c|c|c|c|}
\hline \multicolumn{7}{|c|}{ Saliniy treatment $\left(\mathrm{dSm}^{-1}\right)$} \\
\hline & control & 2 & 4 & 6 & 8 & 10 \\
\hline Root & $8.4 \pm 0.43^{\mathrm{d}}$ & $12 \pm 0.81^{\mathrm{cd}}$ & $15 \pm 1.08^{\mathrm{c}}$ & $23.1 \pm 1.17^{\mathrm{b}}$ & $26.3 \pm 1.43^{\mathrm{b}}$ & $35.1 \pm 3.09^{\mathrm{a}}$ \\
\hline Leaf & $12.6 \pm 1.5^{\mathrm{c}}$ & $19.3 \pm 1.9^{\mathrm{c}}$ & $27.2 \pm 2.2^{\mathrm{b}}$ & $32.8 \pm 1.27^{\mathrm{ab}}$ & $32.5 \pm 2.41^{\mathrm{ab}}$ & $35.7 \pm 3.89^{\mathrm{a}}$ \\
\hline
\end{tabular}

Values are means \pm SE. Values with similar letters are not significantly different.

ence $(P \leq 0.05)$ for total phenolic content was measured among the extracts. The phenol content in the roots and leaves of the hyssop plant significantly increased with increasing salt concentration (Table 2). Content of anthocyanin, was extracted with acidic methanol and measured by a spectrophotometer and calculated as cyanidin 3 -glucoside equivalent. The anthocyanin content of the leaves significantly increased with increasing salinity (Table 3 ).

Table 3

Effect of salinity treatment on the anthocyanin content $\left(\mathrm{mg} \mathrm{g}^{-1} \mathrm{FW}\right)$ in the leaves of Hyssopus officinalis L. plants

\begin{tabular}{|c|c|c|c|c|c|c|}
\hline \multicolumn{7}{|c|}{ Saliniy treatment $\left(\mathrm{dSm}^{-1}\right)$} \\
\hline & control & 2 & 4 & 6 & 8 & 10 \\
\hline Leaf & $375.8 \pm 38.7^{\mathrm{e}}$ & $367.7 \pm 15.8^{\mathrm{d}}$ & $449.2 \pm 19.1^{\mathrm{cd}}$ & $463.5 \pm 13.1^{\mathrm{bc}}$ & $550.3 \pm 39.9^{\mathrm{ab}}$ & $607.5 \pm 34.2^{\mathrm{a}}$ \\
\hline
\end{tabular}

Values are means \pm SE. Values with similar letters are not significantly different.

\section{DISCUSSION}

Under normal conditions, reactive oxygen species (ROS) are effectively scavenged by antioxidant systems. However, when plants are subjected to environmental stresses involving salinity, ROS formation overcomes the antioxidant system capacity [40]. These cytotoxic ROS can seriously destroy normal metabolism through the oxidative damage of lipids, proteins, and nucleic acids [28]. In response to oxidative stress, plants have developed defense systems to scavenge the ROS which is composed of low-molecular mass antioxidants (glutathione, ascorbate and carotenoids) as well as ROS-scavenging enzymes, such as SOD, CAT, POX, APX and GR [28, 40]. ROSscavenging enzymes are capable of protecting the cells from oxidative injury [26]. The enzyme SOD is involved in scavenging reactive oxygen species in the chloroplast. SOD is a key enzyme responsible for the degradation of superoxide radicals resulting in hydrogen peroxide production. Superoxide is rapidly converted to $\mathrm{H}_{2} \mathrm{O}_{2}$ by SOD activity [40]. In this study, increasing concentrations of salt stress caused a significant increase in total SOD activity in the leaves and roots of hyssop plants. An increase in SOD activity [26, 28, 40] has also been obtained in previous studies. 
In the present work, SOD activity test indicated that increase in SOD activity helped to reduce oxidative damage to biomolecules [6] and be a defensive mechanism developed by Hyssopus officinalis plants against salt stress. Similar results were reported [28]. POD is widely distributed in higher plants where it is involved in various processes, including lignification, auxin metabolism, salt tolerance and heavy metal stress [30]. Therefore, POD has often served as a parameter of metabolism activity during growth alterations and environmental stress conditions. GPX activity increased with salinity concentration, a significant increase in GPX activity was observed in leaves and roots. These results are consistent with the findings of [17]. In leaves of rice plant, salt stress preferentially enhances the content of $\mathrm{H}_{2} \mathrm{O}_{2}$ and the activities of SOD, APX, and GPX, whereas it decreases catalase activity [35]. Enhancement in the peroxidase activity as a result of soil salinity was also verified in Morus alba [35]. Further, the activities of SOD and POD, two essential components of antioxidant defense system, both increased under stress treatments. Thus increased POD and SOD activities might enable plants to protect themselves against salt stress. These results suggest that the increased POD activity could contribute to the antioxidant mechanism of Hyssopus officinalis seedlings against higher salt concentrations stress. CAT converts $\mathrm{H}_{2} \mathrm{O}_{2}$ to water and molecular oxygen in peroxisomes [28]. CAT is the most effective antioxidant enzymes in preventing oxidative damage [27]. Increasing concentrations of salt stress caused a significant increase in total CAT activity in the leaves and roots of hyssop plants. Similar to our findings, increased CAT activity in Cassia angustifolia L. [1], maize [4], Jatropha curcas [17], Calendula officinalis L. [12] and Sesamum indicum [24] differing in salt tolerance was found. The results show that increased CAT activity coordinated with the changes of SOD and POD activities plays an important protective role in the ROS-scavenging process and the active involvement of these enzymes are related, at least in part, to salt-induced oxidative stress tolerance in Hyssopus officinalis plants. Compatible solutes such as proline have been shown to accumulate in plants under osmotic (salinity as well as drought) stress, indicating a protective or a regulatory role [3, 42]. It helps in maintaining desired osmotic potential (i.e. involved in osmotic adjustment), protect various cellular components (membranes, proteins/enzymes and nucleic acids) and maintain cellular redox [38]. Many plants accumulate proline as a nontoxic and protective osmolyte under saline conditions [28]. The results showed that the amount of proline increased significantly with salt concentration. Similar results were reported in plants under salt stress [2,28]. Proline is accumulated in leaves, stems, and roots of Pringlea antiscorbutica and this osmolyte was shown to accumulate at a 2-3 higher concentration in the cytoplasm than in the vacuole [28]. Sadder et al. [33] showed that free proline content in leaves of Atriplex halymus increased with increasing salt concentration. Increased proline in high concentrations of salt can lead to osmotic adjustment. Leaf phenolic contents are important protective components of plant cells. The potential of phenolics to act as an antioxidant is mainly due to their properties to act as hydrogen donators, reducing agents and quenchers of singlet $\mathrm{O}_{2}$ [14]. The synthesis of phenolics is generally affected in response to different biotic/ abiotic stresses including salinity [29] and increased phenolic contents were observed 
in wheat cultivars leaves in growth stage under saline conditions [2]. Along with increasing salinity the concentration of phenolic content increased in the leaves and roots of hyssop. Similar results were reported in Nigella sativa showing that the phenolic contents were also affected significantly due to salt stress [7]. Queslati et al. [31] demonstrated the increase of phenols following saline treatment of Mentha pulegium. Salinity stress-induced total phenolic content accumulation has also been previously observed in strawberry and sugarcane [14]. The results suggest that the increasing of total phenolic content in hyssop as a result of salt stress is believed to protect the plant from oxidative damage. Anthocyanins have a wide range of biological activity such as antioxidant, photoprotection, osmoregulation, heavy metal ions chelation, antimicrobial and antifungal activities, which help plants to survive under different stress conditions. Under salinity, the level of anthocyanins in hyssop increased significantly in comparison with control. Tereshchenko et al. [36] reported that the level of anthocyanins increased significantly in bread wheat (Triticum aestivum L.) under salinity and drought stress. Experiments in whole-plant systems have shown similar results. Anthocyanin accumulation induced by salinity conditions was observed in Zea mays roots, Morus alba leaves and the lower stems of Casuarina equisetifolia seedlings [10]. Enhanced synthesis of secondary metabolites under stressful conditions is believed to protect the cellular structures from oxidative damage [9]. These results suggest that salinity tolerance of Hyssopus officinalis plants might also be closely related with the increased capacity of antioxidative system to scavenge reactive oxygen species and with the accumulation of osmoprotectant proline, phenol and anthocyanine contents under salinity conditions.

\section{REFERENCES}

1. Agarwal, S., Pandey, V. (2004) Antioxidant enzyme responses to $\mathrm{NaCl}$ stress in Cassia angustifolia. Biol. Plant. 48, 555-560.

2. Ashraf, M. A., Ashraf, M., Ali, Q. (2010) Response of two genetically diverse wheat cultivars to salt stress at different growth stages: leaf lipid peroxidation and phenolic contents. Pak. J. Bot. 42, 559565 .

3. Ashraf, M., Foolad, M. R. (2007) Roles of glycine betaine and proline in improving plant abiotic stress resistance. Environ. Exp. Bot. 59, 206-216.

4. Azevedo Neto, A. D., Prico, J. T., Eneas-Filho, J., Braga de Abreu, C. E., Gomes-Filho, E. (2006) Effect of salt stress on antioxidative enzymes and lipid peroxidation in leaves and roots of salt-tolerant and salt-sensitive maize genotypes. Environ. Exp. Bot. 56, 235-241.

5. Bates, L. S., Waldreman, R. P., Teare I. D. (1973) Rapid determination of free proline for water stress studies. Plant Soil. 39, 205-207.

6. Becana, M., Dalton, D. A., Moran, J. F., Iturbe-Ormaetxe, I., Matamoros, M. A., Rubio, M. C. (2000) Reactive oxygen species and antioxidants in legume nodules. Physiol. Plant. 109, 372-381.

7. Bourgou, S., Kchouk, M. E., Bellila, A., Marzouk, B. (2010) Effect of salinity on phenolic composition and biological activity of Nigella sativa. Acta Hortic. 853, 57-60.

8. Bradford, M. M. (1976) A Rapid and sensitive method for the quantification of microgram quantities of protein utilizing the principle of protein-dye binding. Anal. Biochem. 72, 248-254.

9. Buchanan, B. B., Gruissem, W., Jones, R. (2000) Biochemistry and Molecular Biology of Plants. The American Society of Plant Physiologists.USA. Maryland. 
10. Chalker-Scott, L. (2002) Do anthocyanins function as osmoregulators in leaf tissues? Adv. Bot. Res. $37,103-127$.

11. Chance, B., Maehly, A. C. (1955) Assay of catalase and peroxidises, Method Enzymol. 2, 764-775.

12. Chaparzadeh, N., D’Amico, M. L., Khavari-Nejad, R. A., Navari-Izzo, F. (2004) Antioxidative responses of Calandula officinalis under salinity conditions. Plant Physiol. Biochem. 42, 695-701.

13. Dai, L. P., Xiong, Z. T., Huang, Y., Li, M. J. (2006) Cadmium-induced changes in pigments, total phenolics and phenylalanine ammonia-lyase activity in fronds of Azolla imbricata. Environ. Toxicol. $21,505-512$.

14. Daiponmak, W., Theerakulpisutb, P., Thanonkaoc, P., Vanavichitd A., Prathephaa, P. (2010) Changes of anthocyanin cyanidin-3-glucoside content and antioxidant activity in Thai rice varieties under salinity stress. Sci. Asia 36, 286-291.

15. Dazy, M., Jung, V., Férard, J., Masfaraud, J. (2008) Ecological recovery of vegetation on a cokefactory soil: Role of plant antioxidant enzymes and possible implication in site restoration. Chemosphere 74, 57-63.

16. Fathiazad, F., Hamedeyazdan, S. (2011) A review on Hyssopus officinalis L.: Composition and biological activities. Afr. J. Pharm. Pharmacol. 5, 1959-1966.

17. Gao, S., Ouyang, C., Wang, S., Xu, Y., Tang, L., Chen, F. (2008) Effects of salt stress on growth, antioxidant enzyme and phenylalanine ammonialyase activities in Jatropha curcas L. seedlings. Plant Soil Environ. 54, 374-381.

18. Giannopolitis, C. N., Reis, S. K. (1977) Superoxide dismutase I. Occurrence in higher plants. Plant Physiol. 59, 309-314

19. Harborne, J. B., Williams, C. A. (2000) Review: Advances in flavonoid research science 1992. J. Phytochem. 55, 481-504.

20. Iqbal, M., Ashraf, M. (2006) Does seed priming induce changes in the levels of some endogenous plant hormones in hexaploid wheat plants under salt stress? J. Integr. Plant Biol. 48, 181-189.

21. Jaleel, C., Gopi, R. (2007) Responses of antioxidant defense system of Catharanthus roseus (L.) G. Don. to paclobutrazol treatment under salinity. Acta Physiol. Plant. 29, 205-209.

22. Jayasinghe, C., Gotoh, N., Aoki, T., Wada, S. (2003) Phenolics composition and antioxidant activity of sweet basil (Ocimum basilicum L.). J. Agric. Food Chem. 51, 4442-4449.

23. Kizil, S., Toncer, O., Ipek, A., Arslan, N., Saglam S., Khawar, K. M. (2008) Blooming stages of Turkish hyssop (Hyssopus officinalis L.) affect essential oil composition. Acta Agric. Scand, Sect. B. $58,273-279$.

24. Koca, H., Bor, M., Özdemir, F., Türkan, İ. (2007) The effect of salt stress on lipid peroxidation, antioxidative enzymes and proline content of sesame cultivars. Environ. Exp. Bot. 60, 344-351.

25. Lavid, N., Schwartz, A., Lewinsohn E., Tel-Or, E. (2001) Phenols and phenol oxidases are involved in cadmium accumulation in the water plants Nymphoides peltata (Menyanthaceae) and Nymphaeae (Nymphaeaceae). Planta 214, 189-195.

26. Miller, G. A. D., Suzuki, N., Ciftci-Yilmaz, S. U. L. T. A. N., Mittler, R. O. N. (2010) Reactive oxygen species homeostasis and signalling during drought and salinity stresses. Plant cell environ. 33, 453467.

27. Nayyar, H., Gupta, D. (2006) Differential sensitivity of C3 and D4 plants to water deficit stress: Association with oxidative stress and antioxidant. Environ. Exp. Bot. 58, 106-113.

28. Parida, A. K., Das, A. B. (2005) Salt tolerance and salinity effects on plants: a review. Ecotoxicol. Environ. Safe. 60, 324-349.

29. Parida, A., Das, A. B., Sanada, Y., Mohanty, P. (2004) Effects of salinity on biochemical components of the mangrove Aegiceras corniculatum. Aquat. Bot. 80, 77-87.

30. Passardi, F., Cosio, C., Penel, C., Dunand, C. (2005) Peroxidases have more functions than a Swiss army knife. Plant Cell Rep. 24, 255-265.

31. Queslati, S., Karray-Bouraoui, N., Attia, H., Rabhi, M., Ksouri, R., Lachaal, M. (2010) Physiological and antioxidant responses of Mentha pulegium (Pennyroyal) to salt stress. Acta Physiol. Plant. 32 289-296. 
32. Roitto, M., Rautio, P., Julkunen-Tiitto, R., Kukkola, E., Huttunen, S. (2005) Changes in the concentrations of phenolics and photosynthates in Scots pine (Pinus sylvestris L.) seedlings exposed to nickel and copper. Environ. pollut. 137, 603-609.

33. Sadder, M. T., Anwar, F., Al-Doss, A. A. (2013) Gene expression and physiological analysis of Atriplex halimus (L.) under salt stress. Aust. J. Crop Sci. 7, 112-118.

34. Singleton, U. L., Rossi, J. A. (1965) Colorimetry of total phenolics with phosphomolybdic- posphotungustic acid reagent. Am. J. Enol. Vitic. 16, 144-158.

35. Sudhaker, C. H., Lakshmi, A., Giridarakumar, S. (2001) Changes in the antioxidant enzyme efficacy in two high yielding genotypes of mulberry (Morus alba L.) under $\mathrm{NaCl}$ salinity. Plant Sci. 161, 613-619.

36. Tereshchenko, O. Y., Gordeeva, E. I., Arbuzova, V. S., Khlestkina, E. K. (2012) Anthocyanin pigmentation in Triticum aestivum L.: Genetc basis and role under abiotic stress conditions. J. Stress Physiol. Biochem. 8, pp.16.

37. Verbruggen N., Hermans, C. (2008) Proline accumulation in plants, Amino acids 35, 753-759.

38. Verdoy, D., De La Peña, T. C., Redondo, F. J., Lucas, M. M., Pueyo, J. J. (2006) Transgenic Medicago Truncatula plants that accumulate proline display nitrogen-fixing activity with enhanced tolerance to osmotic stress. Plant Cell Environ. 29, 1913-1923.

39. Wolski, T., Baj, T., Kwiatkowski, S. (2006) Hyzop lekarski (Hyssopus officinalis L.) zapomniana roślina lecznicza, przyprawowa oraz miododajna. Annales Universitatis Mariae Curie-Sklodowska Lublin-Polonia. 61, 1-10.

40. Yazici, I., Türkan I., Sekmen, A. H., Demiral, T. (2007) Salinity tolerance of purslane (Portulaca oleracea L.) is achieved by enhanced antioxidative system, lower level of lipid peroxidation and proline accumulation. Environ. Exp. Bot. 61, 49-57.

41. Zheljazkov, V. D., Astatkie, T. Hristov, A. N. (2012) Lavender and hyssop productivity, oil content, and bioactivity as a function of harvest time and drying. Ind. Crops Prod. 36, 222-228.

42. Zhu, H., Chen, X., Pan, X., Zhang, D. (2011) Effects of chloramphenicol on pigmentation, proline accumulation and chlorophyll fluorescence of maize (Zea mays) seedlings. Int. J. Agric. Biol. 13, $677-682$ 